\title{
EDITORIAL
}

\section{Recursos Humanos en Salud: Las Tareas Pendientes}

Después de una era de avances espectaculares en salud, el siglo XXI llegó con una doble crisis: dramáticos retrocesos -con caída de la expectativa de vida en los países más pobres y aparición de nuevas pandemias- y débiles respuestas para revertirlos. Demás está decir que, si estos problemas no son atendidos oportunamente, influirán negativamente en las condiciones de salud global por décadas.

Pero la solución no se ve tan simple, toda vez que, en un mundo crecientemente interdependiente, los recursos humanos en salud viven su propia crisis. De acuerdo al informe estratégico de la Iniciativa de Aprendizaje Conjunto en Recursos Humanos para la Salud, el número de trabajadores en esta área es insuficiente en la mayoría de los países, los especialistas están mal distribuidos, los salarios bajos y los ambientes de trabajo precarios no fomentan el desarrollo de la fuerza laboral y la base de conocimientos con que ésta cuenta es exigua. Además, la evidencia muestra que los profesionales capacitados migran de los países pobres a los ricos, de los sectores rurales a las grandes ciudades y del sector público al privado en busca de mejores perspectivas profesionales y económicas, aumentando la mala distribución y el desequilibrio.

Esta realidad se da pese a que está demostrado que la falta de recursos humanos capacitados es quizás el mayor impedimento para la provisión de servicios de salud adecuados y oportunos. El aumento en la expectativa de vida en el último siglo fue favorecido en gran medida, además de mejoramientos significativos en la situación socioeconómica, por la existencia de una fuerza de trabajo sustentada en el perfeccionamiento científico, formalmente organizada y bien formada. En otras palabras, los logros en salud, incluyendo programas efectivos de control de enfermedades, fueron posibles porque se ha contado con estrategias de desarrollo de los recursos humanos exitosas.

Es que los centros de salud, hospitales, clínicas y servicios de salud son tan buenos como la gente que los conforma. Los recursos humanos son el vínculo que amalgama todos los esfuerzos para superar las crisis. En cuanto a las reformas en salud, la participación de la fuerza de trabajo es especialmente importante: una persona motivada puede ser líder e implementar innovaciones; mal tratada, puede constituir un serio obstáculo. De hecho, no se reportan reformas en salud exitosas sin la participación de los trabajadores. Descuidar al recurso humano es, en esta perspectiva, malgastar los otros. Es, pues, un tema de gestión.

Bajo estas premisas, las principales agencias internacionales y 118 representantes de 29 países se reunieron el año 2005 en Toronto, Canadá, con el fin de discutir los desafíos que enfrenta la fuerza regional de trabajo en salud de las Américas. De ese encuentro emanó el "Llamado a la acción de Toronto", documento que apela a todas las naciones a movilizar voluntades políticas, recursos financieros y actores institucionales para contribuir al desarrollo de los recursos humanos en salud. Ello, como un medio para alcanzar los Objetivos de Desarrollo del Milenio y el acceso universal a los servicios de salud de calidad para todos los habitantes de la región al término de la Década de los Recursos Humanos en Salud, es decir, el año 2015.

El "Llamado a la Acción" se centró en aspectos como la alineación de las políticas de recursos humanos con las necesidades de salud específicas de los países, la ubicación de las personas precisas en los lugares adecuados y la administración de los procesos de migración del personal de salud. Además, el llamado puso énfasis en la adecuación y coordinación de los procesos educativos en las instituciones académicas con las necesidades de los servicios de salud, así como en la motivación de la fuerza de trabajo mediante adecuadas compensaciones, ambientes laborales apropiados y posibilidades de desarrollo profesional.

Todo ello ha de darse en un entorno que ha cambiado vertiginosamente en menos de dos décadas 
y que genera importantes brechas entre la oferta y las necesidades de personal de salud. La industrialización, la concentración urbana, la explosión tecnológica y la aparición de nuevas enfermedades asociadas a los estilos de vida actuales, nos ponen ante un escenario en el que se requiere de un nuevo profesional con conocimientos y capacidad para ejercer liderazgo, tomar decisiones, trabajar en equipo, comunicar y difundir el conocimiento.

Dotar al país de equipos de salud que reúnan estas características es una tarea que no sólo atañe a las autoridades de salud, sino también, y en forma muy relevante, a las instituciones formadoras. Entre éstas, las universidades tienen un rol fundamental. Ellas tienen la responsabilidad de entregar a la sociedad profesionales y técnicos altamente calificados y capaces de responder eficientemente a las demandas de salud de la población, comprometidos con su realidad y sensibles ante los problemas de la gente, especialmente la más pobre.

Con esa mirada, la Universidad de Chile, a través de la Escuela de Salud Pública, trabaja intensamente en la renovación de sus programas académicos y en el establecimiento de alianzas estratégicas con los distintos actores involucrados en la formación de recursos humanos en salud. Es así como -en el marco de un convenio suscrito con OPS/OMS-, la Unidad de Desarrollo de Recursos Humanos del organismo internacional, en conjunto con la Escuela, espera realizar un estudio de caracterización de la fuerza laboral en salud pública en Chile. La ESP también está colaborando con el Ministerio de Salud en el relanzamiento del Observatorio de Recursos Humanos en Salud y, recientemente, ha sido designada para preparar la versión chilena del proyecto CIRHUS.

De este modo, con la colaboración activa de las instituciones nacionales y los organismos internacionales, podremos continuar construyendo en nuestra región mecanismos para fortalecer a un sector que, por muchos años, no ha contado con la prioridad de criterios y recursos para el óptimo desempeño que demandan sus funciones, las que, ciertamente, son clave en la sociedad.

Giorgio Solimano

Director 